\title{
Responding to the needs of victims of Islamophobia
}

\section{Introduction}

Support for victims of crime is a fundamental part of a civilised justice system. However, in the current climate of austerity - with the police, courts, prisons, probation and support services facing significant financial cuts - the criminal justice system in the UK falls short of meeting the different and changing needs of communities across the country. As I write this chapter, the police service face a 20 per cent cut in their budget. Undoubtedly, this reality challenges the capacity of police forces to tackle crime, and raises concerns about the quality of service offered to victims of crime. Broadly speaking, victims often need emotional and practical support to recover from the consequences of crime and support services should aim to achieve this outcome. Criminal justice practitioners - particularly those based in diverse communities - must have sufficient knowledge and understanding of the specific needs of their clients (Ahmed, 2009). This a contributing factor to offering a more responsive service, which is accessed by the so-called 'hard-to-reach' or 'hidden' communities. Crime, even when seemingly 'low level', can have a devastating impact upon victims, particularly where a person is deliberately or persistently targeted. This should be taken into consideration when support is provided to victims of hate crime, where they are targeted on their actual or perceived disability, race, religion, gender identity or sexual orientation.

Against this background, Muslims emerge as the largest faith group experiencing hate crimes (Ahmed, 2012). In a post-9/11 climate, there is an increase in violent attacks targeting Muslims, those perceived to be Muslims, and mosques in the West. In the British context, for example, there has been a rise in violent assaults some fatal - on British and other Muslims living in the UK, in verbal and physical attacks towards Muslim women who wear headscarves (hijab) and face veils (niqab), and in the alarming growth in the number of mosques, cemeteries, Islamic centres and Muslim properties that have been the targets of criminal damage, such as graffiti and arson attacks (Engage, 2010). The establishment of, and subsequent demonstrations by, the English Defence League have contributed to this reality of a rising anti-Islamic, antiMuslim hostility. Similarly, the British National Party has launched a highly explicit Islamophobic campaign on the basis of resisting the 'Islamification of the UK'. Since November 2012, a new far-right political party called 'True Brits', which consists of former members of the British National Party, operates throughout the UK. In Europe, support for far-right political parties and street-based movements is also on the increase (Bartlett, Birdwell and Littler, 2011), whilst Islamophobia is becoming increasingly 'institutionalised'. Correspondingly, Switzerland has prohibited future construction of minarets on their soil while France, Belgium and Italy have criminalised the Muslim veil through legislation, which bans the wearing of the face veil in public places. Opposition to the face veiling, and indeed Islam at large, encompasses calls to implement similar legislation in Spain, the Netherlands, Scandinavia, Germany, Canada and Australia. 
With these points in mind, this chapter outlines the link between academic research, policy and practice in relation to offering support to individuals who have suffered Islamophobic hate crime/incidents, whether through verbal abuse or physical injury. First, I examine theory in order to identify the specific religious and cultural needs of victims of Islamophobia. Secondly, I assess contemporary policy and practice by looking at the effectiveness of criminal justice responses to this victimisation within the UK. Statutory criminal justice agents, such as the police and Victim Support, in parallel with faith-sensitive voluntary organisations, such as the Measuring AntiMuslim Attacks programme and the Muslim Youth Helpline, provide support to victims of Islamophobia. However, there are often barriers to the effective delivery of conventional support services, including a lack of understanding and awareness of victims' distinct cultural norms and religious practices. Thirdly, I consider what more we can do to alleviate the impact that this victimisation can have upon victims in terms of offering intelligent support to them, and to this end 'getting it right' for victims of Islamophobia. Within the discussions that follow I make the case for a more flexible and effective approach to engaging with victims of Islamophobia; one which facilitates greater communication between statutory and voluntary service providers and community-based Muslim organisations such as mosques, Islamic schools and Islamic community centres.

\section{Islamophobia and its impact upon victims}

Islamophobia has been described by Chakraborti and Zempi (2012: 271) as 'a fear or hatred of Islam that translates into ideological and material forms of cultural racism against obvious markers of 'Muslimness'. Within this framework, Islamophobia can be interpreted through the lens of cultural racism whereby Islamic religion, tradition and culture are seen as a 'threat' to 'national identity', whilst 'visible' Muslims are viewed as 'culturally dangerous' and threatening the 'British/Western way of life'. In this context, Islam and Muslims find themselves under siege. Muslim men have emerged as the new 'folk devils' of popular and media imagination, being portrayed as the embodiment of extremism and terrorism, whilst Muslim women have emerged as a sign of gender subjugation in Islam, being perceived as resisting integration by wearing a headscarf or worse still the face veil. Such stereotypes provide fertile ground for expressions of Islamophobia in the public sphere. Following this line of argument, Islamophobia manifests itself as an expression of anti-Islamic, anti-Muslim hostility towards individuals identified as Muslims on the basis of their 'visible' Islamic identity. Expressions of Islamophobia include verbal abuse and harassment, threats and intimidation, physical assault and violence (including sexual violence), property damage, graffiti, offensive mail and literature, and offensive online and internet abuse.

The research evidence suggests that since 9/11 Muslims have been particularly vulnerable to harassment, intimidation and violence when displaying visible signs of their faith. McGhee (2005) observes that there was a four-fold increase in the number of racist attacks reported by British Muslims and other Asian, ostensibly 'Muslim- 
looking', groups in the UK during the months immediately after 9/11. This heightened sense of vulnerability since 9/11 has also been reported in Garland and Chakraborti's (2004) studies of racism in rural England. In the three weeks following the $7 / 7$ bombings, police figures showed a six-fold increase in the number of religiously motivated offences reported in London, the vast majority of which were directed against Muslim households and places of worship, whilst in the same three-week period over 1,200 suspected Islamophobic incidents were recorded by police force across the UK (BBC, 2005). As of 2012, the latest police figures in line with academic research indicate that anti-Muslim hate crimes are currently at record levels compared to the beginning of the decade. From 9/11 until 2010, successive Crown Prosecution Service (CPS) racist incident monitoring reports highlight that Muslims have accounted for more than half of all incidents of religiously aggravated offences at 54 per cent, whilst up to 60 per cent of mosques, Islamic centres and Muslim organisations have suffered at least one attack (Ahmed, 2012). In 2011, over half of British Muslims reported having experienced at least one incident of Islamophobic abuse, harassment or intimidation in public (Ahmed, 2012).

Muslim women in veil have been particularly vulnerable to manifestations of Islamophobia in the public sphere on the basis that they are easily identifiable as Muslim. From this premise, 'visibly' Muslim women may be targeted because they are seen as more visually 'threatening' than Muslim men, particularly when they wear the full veil (Chakraborti and Zempi, 2012). At the same time, popular perceptions of veiled Muslim women as submissive, oppressed or subjugated render them 'easy subjects' against whom to enact Islamophobic attacks (Chakraborti and Zempi, 2012). GithensMazer and Lambert (2010), whose research included interviews with victims, perpetrators and witnesses of anti-Muslim hate crimes in London, found that veiled Muslim women have become widespread targets for verbal and physical abuse, including being spat upon and having their veils torn from them. This line of argument highlights the vulnerability of veiled Muslim women to Islamophobic attacks in the public sphere.

Similar to any crime, Islamophobic victimisation carries a human cost: it can have a devastating and long term impact upon victims, particularly those who are the most vulnerable such as women, disabled and elderly Muslims. The emotional effects of this victimisation might include fear (particularly of repeat attacks), anger, posttraumatic stress, depression, anxiety as well as physical symptoms, including panic attacks. In some cases the impact of Islamophobic victimisation is so severe that it can cause victims to change the way that they live their lives because the emotional trauma makes them afraid to leave their house. Tarlo (2007) reveals the reluctance of both hijab and niqab wearers to visit areas in London where they will be in a sartorial minority. Moreover, some Muslims are driven to adopt Western names and pretend not to be Muslims at all, whilst others emphasise their Asian-ness in order to draw boundaries between themselves and other 'visible' Muslims (Afshar, 2008).

For those subjected to more violent attacks, the impact can be life-changing injury or bereavement. In July 2009, Marwa al-Sherbini, a 32-year-old Egyptian pharmacist, who was three months pregnant at the time, was stabbed to death in a 
German courtroom whilst preparing to give evidence against a German man of Russian descent, who had tried to remove her Muslim headscarf and had called her an 'Islamist', 'terrorist' and 'whore' in a public park in Dresden, Germany (BBC, 2009). In May 2010, a Muslim woman was attacked by a robber who stole thousands of pounds worth of valuables before wrapping her in a carpet, setting fire to her and then saying: 'This is your Eid present, you Muslim' (MailOnline, 2010). It was during Friday prayers at the end of Ramadan ${ }^{1}$ when this incident occurred in the victim's house in London. Islamophobic victimisation is unique in the consciousness of the wider Muslim community through reference to the notion of ummah (the worldwide community of Muslim believers). Whether Islamophobic attacks are targeted at people or buildings, Islamophobic victimisation is commonly perceived by the victim to be an attack on Islam and Muslims as a whole (see also Chakraborti and Zempi, 2013).

At the same time though, victims of Islamophobia are not a homogenous group. Experiences and effects of manifestations of Islamophobia are likely to be shaped by a range of characteristics of the victim such as age, gender, class, education, ethnicity, sexuality, geographical location and socio-economic status. However, little focus has been given to the intersectionality across victims' multiplicity of identities, or even to multiple disadvantage. This line of argument indicates the complex needs of some victims of Islamophobia, such as individuals who are disabled, or those who do not speak English, and those suffering from domestic or sexual violence. Also, refugees and asylum seekers are faced with specific barriers, including a lack of awareness of the existence of support services and language difficulties. When these multiple factors are combined with each other, it becomes clear that victims experience a range of intersectional issues and this should be taken into account when needs are assessed and support is provided. Certainly, the experience of receiving support should minimise the suffering of victims and not inadvertently add to it. In what follows, I review the range of services available before analysing the strengths and weaknesses of these services in terms of their capacity to address the distinct religious and cultural needs of victims of Islamophobia.

\section{Contemporary support services}

At the time of this writing, Victim Support is the government's primary provider of victim and witness support services in England and Wales. ${ }^{2}$ Victims have access to face-to-face and over the telephone, emotional and practical support provided by Victim Support through the police automatically referring victims to these services, unless they choose not to be referred. In essence, Victim Support services are designed to offer support to all those referred by the police rather than specialising in support for those in greatest need, and of course, not all victims are willing to contact the police themselves.

\footnotetext{
${ }^{1}$ Eid is a Muslim holiday that marks the end of Ramadan, the Islamic holy month.

${ }^{2}$ Victim Support is a locally-based organisation, backed up by a national infrastructure. It has evolved from a federation of 77 independent local charities to a single national charity in 2008 (Victim Support, 2012).
} 
This 'one size fits all approach' is potentially flawed for victims of Islamophobia on the basis that it does not take into consideration distinctive faith and cultural needs. Based on my qualitative research in relation to the targeted victimisation of veiled Muslim women in public, victims were less likely to access the police and as a result Victim Support services because of both religious and cultural factors (Zempi, forthcoming 2014). ${ }^{3}$ For example, victims reported that they found it difficult to engage with male police officers and support workers, whilst others stated that they found it challenging to visit an organisation such as the police or Victim Support. At the same time, some victims did not have any knowledge of Victim Support and its services.

In addition to conventional support services such as Victim Support, both the Ministry of Justice and the Home Office provide funds to other voluntary organisations that offer support to victims of crime. In the context of Islamophobia, support services include the Measuring Anti-Muslim Attacks (MAMA) programme and the Muslim Youth Helpline (MYH). Launched in 2012, the MAMA programme is a non-profit organisation which is co-ordinated and implemented by an interfaith organisation, Faith Matters. It offers services to Muslims in England, to individuals perceived to be Muslims (e.g. Sikhs) and who have suffered attacks, and to Muslims who have been attacked by other Muslims because they are perceived to be from a minority group within Muslim communities (MAMA, 2012). The scheme operates as an alternative reporting system on the basis that if victims want the attack logged and passed onto the police (but they are not willing to contact the police themselves) MAMA will do this on their behalf. There are various ways that victims can report to the MAMA programme including via a freephone number, sms, facebook, twitter, e-mail and online. As such, the MAMA programme contributes to supplementing official statistics through a variety of reporting mechanisms, including the use of social networking sites.

One of the strengths of the scheme is that it contributes to bridging the gap between official data and the true extent of the problem of Islamophobia through mapping, measuring and analysing data on cases received. Although the vast majority of incidents to date have been incidents of hostility and violence targeted towards Muslims and people perceived to be Muslims, ${ }^{4}$ a quarter of cases involved dissemination of antiMuslim literature, whilst over ten per cent of cases involved an attack on mosques and other Muslim related physical sites (MAMA, 2012). Correspondingly, the scheme uses 'crowdmapping' software to compile results of attacks - whether physical, verbal, written or online - into a special database, which is then distributed to police forces across the UK. ${ }^{5}$

\footnotetext{
${ }^{3}$ This study explores the lived experiences of veiled Muslim women as victims of Islamophobia in public places in Leicester and elsewhere. The research methodology comprises of individual and focus group interviews with victims, individual interviews with statutory and voluntary service providers, and also, an ethnographic approach which includes wearing the full veil in public places in Leicester.

${ }^{4}$ The findings indicate that Muslim women have been targets of increasing anti-Muslim hostility in public places while children as well as elderly Muslims have also been verbally and physically attacked. In particular, Muslim women who wore the niqab were more likely to be physically attacked on the streets. There have also been hate calls recorded to the MAMA line itself.

${ }^{5}$ Analyses of cases received so far indicate clustering of attacks in London, the West Midlands and Greater Manchester area, including Luton. In line with these cluster areas, the MAMA (2012) findings point to a direct or indirect link between Islamophobic attacks and the English Defence League.
} 
Launched in 2004, the Muslim Youth Helpline (MYH) provides support services to Muslim youth nationally via the telephone, email, internet, online web chat and through the post. Its services include a free and confidential helpline service run by young, male and female, Muslim volunteers, and an online support service called 'muslimyouth.net' (MYH, 2012). In addition to these services, the Muslim Youth Helpline has an advocacy department which supports vulnerable young British Muslims, who might be unable to obtain legal advice from their own resources (MYH, 2012). A core characteristic of the Muslim Youth Helpline is that it operates under the ethos of being youth led. Its services are based on the premise that peer support by Muslim volunteers is the most effective way of empathising with the challenges that young British Muslims face in a post-9/11 climate.

Analyses of the cases received by the Muslim Youth Helpline (2012) shed light on the marginalisation endured by young British Muslims. Issues such as the defamation of the Muslim identity by its relation to extremism and terrorism, a lack of awareness of existing services available (thereby suggesting that many Muslim youth do not benefit from current policies), and a sense of deep mistrust and fear of non-Muslim institutions are amongst the key characteristics of the marginalisation of Muslim youth. Based on the cased received so far, victims reported that they were increasingly reluctant to access mainstream support services for fear of being discriminated against and misunderstood (MYH, 2012). Certainly, if young British Muslims are reluctant to access support from conventional service providers for fear of being misunderstood, the results are likely to be experiences of further isolation and marginalisation. Accordingly, mainstream support services are struggling to identify, contact and ultimately, serve 'hard-to-reach' minority Muslim youth (MYH, 2012). This is especially true at a time when budget cuts are putting pressure on all parts of the criminal justice system and as a result challenge its ability to deliver high quality services for victims of all types of crime, let alone for victims of Islamophobia.

\section{Effectiveness of contemporary practices}

The current public spending reductions in criminal justice and elsewhere, in parallel with significant changes to crime policy (such as the introduction of elected police and crime commissioners) increase our need for a thorough understanding of Islamophobia - in line with any type of crime - through robust, consistent data collection and analysis. Both the MAMA programme and the Muslim Youth Helpline provide Muslim faith and culturally sensitive support services to victims of Islamophobia, whilst attempting to identify the nature and extent of British Islamophobia through the collection, analysis and mapping of anti-Muslim attacks in the country. Clearly, data collection and information gathering are pivotal to 'intelligence-led policing' - currently seen as one of the most positive contributions that policing can make to crime

According to available data, there has been an English Defence League involvement in about a quarter of the cases recorded to date. 
prevention and reduction. However, conventional support services such as Victim Support are designed to offer support to victims of crime referred by the police. Ultimately, this approach masks the true extent of the problem of Islamophobia on the basis that both police figures and Victim Support records ignore the experiences of victims who have not reported this victimisation.

While policy agendas have been heavy with initiatives designed to encourage victims of hate crime to contact the police, remarkably little attention has been directed to understanding the obstacles that stand in the way of victims of Islamophobia from coming forward and reporting this victimisation. Indeed, reporting an incident to the police sets in motion a range of other processes over which the victim has little or no control (Dignan, 2004). These processes may inflict additional costs and further hardship on the victim; a consequence that is understood as 'secondary victimisation' (Dignan, 2004). This is especially true for victims with multiple needs, who have to try to understand and negotiate a complex criminal justice system, which they may never have dealt with before. In my research, victims - that is, veiled Muslim women who have been verbally or physically attacked in public places - cited the frequency of Islamophobic victimisation, the fear of criminal justice procedures and the belief that they would not be taken seriously by the police as the main reasons for their hesitance (Zempi, forthcoming 2014).

Unfortunately, this level of non-reporting translates into hundreds of cases that did not reach any formal complaints bodies. Equally worryingly, this finding indicates that victims did not receive the level of emotional and practical support that they needed. This potentially exacerbates both their vulnerabilities and their invisibility to front-line law enforcers and criminal justice practitioners. This is in line with academic research which highlights the invisibility of hate crimes due to victims' negative perceptions of service providers, fear of reprisals, previous discriminatory experiences, language, religious and cultural barriers, and a historical mistrust of the police (Chakraborti and Garland, 2004; Dignan, 2004; Williams and Robinson, 2004; Sharp and Atherton, 2007; Paterson, Kielinger and Fletcher, 2008; Mythen, Walklate and Khan, 2009; Christmann and Wong, 2010; Githens-Mazer and Lambert, 2010).

At the same time though, change should also come from the Muslim community itself. A contributing factor to the invisibility of this victimisation is the fact that British Muslim communities remain ill-equipped to deal with the current challenges faced by Muslims. Islamophobic victimisation - in line with other sensitive issues such domestic violence, sexual abuse, forced marriages, drugs and alcohol addiction - is not discussed openly within the Muslim community, which can only serve to increase victims' alienation and vulnerability. The reasons for which both schemes, the MAMA programme and the Muslim Youth Helpline, were initially established are likely to remain undiminished: the lack of faith and culturally sensitive support services available to Muslims by conventional support services in parallel with the culture of taboo, shame, silence and condemnation that surround sensitive issues within the Muslim community that together prevent victims from seeking help (MYH, 2012). In order to break the silence, it is imperative to break the cycle of non-reporting. This necessitates an 'intelligence-led' service provided by statutory and voluntary service providers in 
synergy with community-based Muslim organisations such as mosques, Islamic schools and Islamic community centres.

\section{Is there a silver lining?}

Governments have a moral and legal responsibility to ensure that first class support such as counselling services and practical advice - is provided to help victims recover from the consequences of crime. However, services are not available all over the country whilst standards are not consistently high (Ministry of Justice, 2012). In the current climate, the criminal justice system falls short of meeting the needs of victims of Islamophobia on the basis that religious and cultural needs are not consistently recognised. It is important that statutory support services such as Victim Support whereby support is mainly offered to those victims who have already contacted the police and agreed to receive support - take steps to improve their outreach work with 'hard-to-reach' communities, whose members are less likely to contact the police. In this context, victim support services should be provided to victims of Islamophobia through an effective and efficient referral system, based on joint working with the police, Victim Support, the MAMA programme, the Muslim Youth Helpline, and local Muslim organisations such as mosques, Islamic schools and Islamic community centres.

In addition to supporting victims of Islamophobia through culturally aware and faith-sensitive counselling and practical assistance, it is important that support services drive social change in order to remove the conditions in which vulnerable Muslims are forced to endure their experiences of Islamophobic victimisation in silence. Taking into consideration that trust and confidence in the criminal justice system promote social integration and contribute to the successful application of the model of community cohesion, the need to dismantle barriers between the criminal justice agencies and victims of Islamophobia becomes apparent. In a climate of growing Islamophobia, the vulnerability of 'visible' Muslims cannot be ignored. Reforms must be made to provide 'at risk' victims with a more accessible and effective mechanism of reporting and, of receiving support, tailored to victims' needs. Accordingly, religious and cultural sensitivity is crucial in offering high-quality support. Service providers need to be trained to deliver a service that is both faith and culturally sensitive. An alternative to this would be to appoint staff members that have some knowledge and understanding of Islam to be able to identify with the background from which victims present themselves.

It is also important to provide adequate language services for recent immigrants who do not speak English, as a language barrier can make the provision of services much more difficult. At the same time, it is important that both policy makers and criminal justice practitioners understand the diversity within the Muslim population which covers ethnicity, nationality and theology but most importantly, gender. Services need to be flexible to meet the needs of (un)veiled Muslim women and these differ considerably from those of Muslim men who have suffered Islamophobic victimisation. For example, access to female staff members is an important need for some Muslim women who will not otherwise access services. Similarly, the option of home visits by 
female police officers and support workers should be made available to veiled Muslim women who have been victims of Islamophobia.

While it is important that support service providers working with victims of Islamophobia recognise both the principles of the religion and the specific cultural backgrounds of those with whom they are working, it is also crucial that sensitivity does not stop there. Support service providers should develop the capacity and flexibility within their programmes to allow repeat victims to return to the organisation for additional and continued support. In order to achieve this, it is essential to empower professionals to exercise their judgement in assessing needs whilst there should be a working assumption that victims of Islamophobia may well require significant support. In cases where victims' needs are not fully recognised, the lack of appropriate support can add to the injury inflicted on the victim. Accordingly, a lack of adequate support services can be a source of distress, disappointment and frustration for those who experience it. It can also make victims feel isolated, which can worsen the distress caused by the crime itself. In some cases it can lead victims to drop out of a case while it is being prosecuted. Clearly, the way in which victims are treated has an impact on the likelihood of crimes being reported in the future.

Pragmatically though, in the current climate of austerity criminal justice agencies and support services are faced with the immense challenge of providing the same quality of service, even as they face significant cuts to their budgets. A lack of resources makes it difficult to meet victims' needs, particularly in relation to vulnerable and marginalised individuals who have a range of complex needs, which compounds the problem further. However, the key to meeting the needs of victims of Islamophobia lies in understanding their distinct cultural and religious needs rather than investing financially. In other words, the silver lining to improving victim support services does not necessarily require more money. This line of argument indicates that much more work needs to be done in the area of recognising victims' needs, which can be costeffective. Ultimately, recognising, understanding and meeting victims' distinct needs is critical to the overall success of the criminal justice system. 